economic importance; at worst, they may precipitate serious exacerbations of chronic bronchitis and other illness, so there are clear indications to prevent colds in susceptible people. Rhinoviruses account for only about $40 \%$ of colds, however, ${ }^{610}$ and clearly it will not be possible to prevent even all of these, since the source of the virus is not always easily recognised. In busy hospitals and general practice, for example, staff are frequently exposed to acute viral infections, and it would be difficult to define what sort of contact would warrant instituting prophylactic treatment. Interferon sprays would have to be cheap and made freely available so that treatment could be started soon enough to be effectiveand in view of the effects on the nasal mucosa, long term treatment may need to be discouraged.

Recent evidence suggests that cold viruses are more likely to be transmitted by direct hand to mucosa contact than by inhaled aerosol droplets. ${ }^{615}$ For the future, interferon holds great promise, but for the present perhaps more emphasis should be put on attempts to reduce transmission of infection by simple hygienic measures-such as diligent handwashing after every contact.

GEOFFREY SCOTT

Senior Registrar in Microbiology,

Whittington Hospital,

London N19 5NF

1 Phillpotts RJ, Tyrrell DAJ. Rhinovirus colds. BrMed Bull 1985;41:386-90.

2 Farr B, Gwaltney JM Jr, Adams KF, Hayden FG. Intranasal interferon-alpha 2 for prevention o natural rhinovirus colds. Antimicrob Agents Chemother 1983;26:31-4

3 Douglas RM, Albrecht JK, Miles HB, et al. Intranasal interferon-alphaz prophylaxis of natural respiratory virus infection. F Infect Dis 1985;151:731-6.

+ Scott GM, Onwubalili JK, Robinson JA, Doré C, Secher DS, Cantell K. Tolerance of one-month intranasal interferon. $\mathcal{f}$ Med Virol 1985;17:99-106.

Hayden FG, Mills SE, Johns ME. Human tolerance and histopathologic effects of long term administration of intranasal interferon-alpha . F Infect Dis 1983;148:914-21.

6 Gwaltney JM Jr. Rhinoviruses. In: Evans AS, ed. Viral infections of humans: epidemiology and control. 2nd ed. New York: Plenum Press, 1982:491-517.

Herzog Ch, Just $M$, Berger $R$, Havas $L$, Fernex $M$. Intranasal interferon for contact prophylaxis agairst common cold in families. Lance 1983;ii: 962

Douglas RM, Moore BW, Miles HB, et al. Prophylactic efficacy of intranasal alpha 2 -interferon in the family setting. $N$ Engl f Med 1986;314:65-70.

Hayden FG, Albrecht JK, Kaiser DL, Gwaltney JM Jr. Prevention of natural colds by contact prophylaxis with intranasal alphaz-interferon. N Engl f Med 1986;314:71-5.

10 Larson HE, Reed SE, Tyrrell DA. Isolation of rhinoviruses and coronaviruses from 38 colds in adults. F Med Virol 1980;5:221-9.

11 Higgins PG, Phillpotts RJ, Scott GM, Wallace J, Bernhardt LL, Tyrrell DAJ. Intranasal interferon as protection against experimental respiratory coronavirus infection in volunteers. Antimicrob Agents Chemother 1983;24:713-5.

12 Dolin R, Betts RF, Treanor J, Erb S, Roth FK, Reichman RC. Intranasally administered interferon as prophylaxis against experimentally induced influenza $\mathrm{A}$ infections in humans. In Spitzy KH, Karrer K, eds. Proceedings of 13th international congress of chemotherapy. Vienna: Egermann, 1983:6:SE4.7/1.7.

13 Phillpotts RJ, Higgins PG, Willman JS, Tyrrell DAJ, Freestone DS, Shepherd WM. Intranasal lvmphoblastoid interferon ("Wellferon") prophylaxis against rhinovirus and influenza virus in volunteers. F Interferon Res 1984;4:535-41.

14 Phillpotts RJ, Scott GM, Higgins PG, Wallace J, Tyrrell DAJ, Gauci CL. An effective dosage regimen for prophylaxis against rhinovirus infection by intranasal administration of HuIFN alpha,. Antiviral Res 1983;3:121-36.

15 Gwaltney JM Jr, Hendley JO. Rhinovirus transmission: one if by air, two if by hand. Am $\mathcal{f}$ Epidemiol 1978;107:357-61.

\section{Steroids, the eye, and general practitioners}

Since their introduction in the early 1950s topical steroids have transformed the management of inflammatory disease of the anterior segment of the eye. Their proper use may be sight saving; their inappropriate use is potentially blinding. While they produce a rapid relief of symptoms, at the same time steroids may mask adverse effects. Patients may exert considerable pressure for their prescription and may misuse them once supplied. More than 30 years have passed since Thygeson et al first pointed out the potential hazards'; these have been confirmed and documented many times, and warnings now appear in textbooks, the British National Formulary, and MIMS.

Herpes simplex of the cornea is a major ophthalmit problem. A simple dendritic epithelial lesion may converted by treatment with steroids into an extensive "amoeboid" ulcer affecting all the layers of the cornea are requiring prolonged and complicated management with the likelihood of permanent corneal scarring and loss of visiog. These dangers were described in detail at a symposium on herpes simplex eye disease by Williams et $a l^{2}$ and Jones et a who showed how patients given steroids had lesions that were more severe and had increased rates of recurrence areat morbidity. They argued that "no undiagnosed red eye shoud ever be treated with steroids before referral to an ophtha. mologist" and called for active communication betweeक ophthalmologists and general practitioners to prevent thes misuse.

Bacterial and fungal invasion may also be potentiated by the use of topical steroids. A simple corneal abrasion may become infected. Such infections, particularly wiff organisms of the pseudomonas group, may progress to panophthalmitis within hours. The increasingly widespre蛋 use of soft contact lenses is an added source of problem\$ Such lenses are often difficult to maintain and may themselves be a source of infection.

Prolonged medication with topical steroids may lead $t$ open angle glaucoma. Some patients ("steroid reactors") a a particularly prone to such a rise in intraocular pressure. Though short term ocular hypertension may not be of greât visual significance, prolonged hypertension may lead to $\vec{a}$ cupped disc, field defects, and permanent loss of vision.

Cataracts have been reported after the prolonged systemic use of steroids and also after topical application. Suced cataracts may be treated surgically and are not, therefore quite so disastrous for the patient as infection and glaucome; none the less, they are better avoided.

Against that background doctors should be disturbed thast a questionnaire circulated widely in Britain in 1984 by Claoke and Stevenson found that many ophthalmologists had seen recent examples of the misuse of topical steroids causing serious visual defects (p 1450). The data are to an extent anecdotal but provide a convincing indication of trends. Inca second study Lavin and Rose analysed the previous trea ment of patients attending an eye accident and emergene्s department and found further grounds for concern ( $\mathrm{p} 1448 \%$ They point out the difficulties that general practitioners ha胥 in making a correct diagnosis. This difficulty in diagnosis may lead to the inappropriate use of topical steroids, b㺼 steroids were also sometimes prescribed inappropriate when the diagnosis was correct and other more simple remedies were available.

Topical steroids are used by ophthalmologists in herpes simplex keratitis, but always covered by an appropriaç antiviral drug. Their use requires considerable experien $\tilde{E}^{2}$ and careful microscopic control to titrate the treatme against the clinical condition. This can be carried out only an ophthalmic department and should never be initiater elsewhere.

Communication between the individual ophthalmologis and the general practitioner is paramount, and not merely underline the textbook warnings of adverse effects. THE current papers reiterate the difficulties. Not only should the plea of Jones et al be totally reaffirmed-that topical steroids should never be given for an undiagnosed red eye-but man consultant ophthalmic surgeons believe that no treatme with such drugs should ever be initiated by a gener 
practitioner without an ophthalmic opinion. Nor should treatment be repeated or renewed by general practitioners without regular ophthalmic review to eliminate the possibility of steroid induced glaucoma or the onset of an unsuspected secondary infection. Unfortunately, those most in need of instruction will probably not be reading this journal. The task falls, therefore, on ophthalmologists-who have the problem thrust on them-to reinforce education at a local level. ${ }^{+}$They will have to try and try again to prevent the misappropriate use of topical steroids-an iatrogenic cause of great visual disability. ${ }^{4}$

D St Clair Roberts

Consultant Ophthalmic Surgeon,

Sussex Eve Hospital.

Brighton BN2 5BF

1 Thygeson P. Hogan MJ. Kimura SI. (cortisone and Wodrocortisone in ocular intection

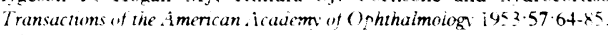

Williams HP. Falcon MG. Jones BR. Corticosteroids in the management of herpetic eve disease. Trans (Iphthalmol Soc i $K$ 1977;97:341-4.

Jones BR. Cister DJ. Falcon MG. Prospects of prevention of recurrent herpetic eye disease. Trans

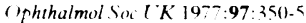

4 Gilkes.MJ. Ophthalmology. Br.Med 7 1982:285:124;-8.

\section{Peripheral neuropathy associated with dysproteinaemia, skin changes, and endocrinopathy}

Connoisseurs of bizarre multisystem syndromes will be delighted by a little known gem from Japan, which is characterised by progressive polyneuropathy, diffuse hyperpigmentation, scleroderma, hypertrichosis, anasarca, various endocrine changes, hepatosplenomegaly, lymphadenopathy, and dysglobulinaemia, usually associated with plasma cell dyscrasia. More than 150 cases of this distinctive disease have now been described under a variety of names, including Shimpo's syndrome, ' Takatsuki syndrome, ${ }^{2}$ PEP syndrome (progressive polyneuropathy associated with pigmentation, oedema, and plasma cell dyscrasia), ${ }^{3}$ POEMS syndrome (plasma cell dyscrasia with polyneuropathy, organomegaly, endocrinopathy, $M$ protein, and skin changes), ${ }^{4}$ and CrowFukase syndrome. Although most reports have come from Japan, several isolated cases or small series have been reported from the United States and Europe. ${ }^{6-12}$

A recent review of 102 Japanese cases showed that 56 of the patients had multiple myeloma, usually associated with osteosclerotic bone lesions and a circulating $\lambda$ light chain. ${ }^{5}$ Of the remaining 46 patients, two had an extramedullary plasmacytoma, 33 had only a serum monoclonal protein, and 11 a raised serum concentration of a polyclonal protein. The clinical features of the syndrome were the same whether multiple myeloma was present or absent.

The age at onset ranged from 27 to 80 , with a male to female ratio of about 2:1. Most patients presented with chronic progressive polyneuropathy, peripheral oedema, or a combination of the two. The neuropathy was of the distal, symmetrical, sensorimotor type, with gradual proximal spread, and in many cases severe weakness prevented the patient from walking. Nerve conduction studies showed that both motor and sensory conduction were slow, and biopsy specimens showed a mixture of axonal degeneration and segmental demyelination. The cranial nerves were almost always spared, but the protein concentration in the cerebrospinal fluid was increased in $94 \%$ of cases, and papilloedema was present in $62 \%$. Anasarca was often present with dependent oedema $(91 \%$, ascites $(62 \%)$, and pleural effusions $40 \%$. Diffuse pigmentation occurred in $93 \%$ of patients, and hypertrichosis, thickened skin, and hyperhidrosis were also common. Most of the men had gynaecomastia and impotence, and many of the women were amencrrhoeic. Less common endocrine disturbances included glucose intolerance and hypothyroidism. Most patients had enlargement of the liver and spleen or generalised lymphadenopathy, and the lymph nodes showed a peculiar histological change known as Castleman's angiofollicular hyperplasia with proliferating arborising capillaries, spindle cell proliferation in the follicle centres, sheets of mature plasma cells in the interfollicular tissue, and clear cut lymph sinuses with sinus histiocytosis. Other common clinical features included mild fever and finger clubbing.

Most patients in this large series were treated with prednisolone, cyclophosphamide, or irradiation; they showed some initial improvement, but many eventually deteriorated and died of the disease. Most deaths were due to heart failure; the mean survival was 33 months from the onset of the symptoms.

Peripheral neuropathy is a rare complication of plasma cell neoplasia, occurring in less than $1 \%$ of all cases, ${ }^{12}$ but at least 170 cases of polyneuropathy associated with dysproteinaemia have been reported outside Japan. ${ }^{5}{ }^{13}$ Only about one third of these have had the cutaneous and endocrine features of the full blown POEMS syndrome, and it is still not certain whether the full syndrome is a separate entity from the peripheral neuropathy alone. In a review of 56 reported cases of neuropathy due to IgM paraproteins Driedger and Pruzanski found evidence of the full syndrome in only six cases, but they commented that features such as mild oedema, scleroderma, pigmentation, hypertrichosis, hyperhydrosis, impotence, and amenorrhoea may go unnoticed or unreported. ${ }^{12}$ This suggestion is supported by the data of Kelly et al, who carefully studied 16 non-oriental patients with multiple myeloma and peripheral neuropathy and found that only one had none of the other features of the syndrome and that 12 patients had three or more of the other features. ${ }^{13}$

The pathogenesis of this syndrome is puzzling. It seems likely that the abnormal protein is implicated in the nerve damage, and binding of immunoglobulin to nerve and myelin sheaths has been reported in some patients, but the importance of this is uncertain, since the same finding may occur in patients with myeloma without neuropathy. ${ }^{14}$ Mice repeatedly injected with the monoclonal protein from patients with myeloma do, however, develop a demyelinating polyneuropathy. ${ }^{15}$ Some of the features of the syndrome such as water retention, pigmentation, gynaecomastia, impotence, and amenorrhoea might be explained by increased oestrogen production. Urinary oestrogen concentrations were increased in 11 of the 19 patients in whom they were measured, ${ }^{5}$ and two patients have recently been shown to have an increased rate of conversion of androgen to oestrogen. ${ }^{16} \mathrm{~A}$ similar acceleration of exogenous androgen conversion occurs during normal pregnancy and has been used as a test of placental function. Further investigation of this syndrome may thus throw unexpected light on other topics, including the control of sex hormone metabolism.

JOHN L BURTON

Reader in Dermatology,

Bristol Royal Infirmary,

Bristol BS2 8HW 